\title{
Electric Vehicle Load Characteristic Analysis and Impact of Regional Power Grid
}

\author{
Wu Kuihua ${ }^{1, a}$, Niu Xinsheng ${ }^{1, b}$, Wang Jian $^{2, ~ c}$, Wu Kuizhong ${ }^{3, d}, J_{i a}$ Shanjie ${ }^{1, e}$ \\ ${ }^{1}$ Shandong Electric Power Economic Research Institute, Jinan, 250002, China \\ ${ }^{2}$ Shandong Supervision and Inspection Institute for Product Quality, Jinan, China \\ ${ }^{3}$ Jilin electric power company limited, Changchun, China \\ a wukuihua@126.com, b niuxs3701@126.com, ${ }^{\text {c }}$ wangjian4509@126.com, \\ d wukuizhonga@163.com, ${ }^{\mathrm{e}}$ jiashanjie@yahoo.com.cn
}

Keywords: Charging Station; Coordinated Charging; Load Characteristic; Power Grid

\begin{abstract}
With the popularity of electric vehicles, a large number of charging stations connected to the grid, will bring large impact for the power, voltage and current of grid. This paper based on several scenarios of charging modes, such as plug and charge, night charging and intelligent charging, the corresponding EV load models have been established. Finally, an analysis is performed for the load characteristics of Regional power grid to demonstrate the impacts of different EV charging scenarios.
\end{abstract}

\section{Introduction}

Electric vehicles, which are defined as vehicles that can totally or partly use electricity instead of conventional petroleum for propelling, are expected to reduce tailpipe emissions as well as the noise, so developing $\mathrm{EV}$ is an efficient approach to resolve the traffic, energy crisis and environment problem $^{1-2}$. As the number increases, EV will have a huge impact on power grid, such as load characteristics of the original power supply, the planning and operating ${ }^{3}$.In the early years of EV, the influence of the charging station on the power grid can be neglected. As the penetration of EVs becomes higher and higher, both the demand of charging and the number of charging station will increase, so the potential effect on the grid, especially the load profile of grid, will be constantly arising.

This paper investigates the impact of large-scale EVs on the grid, considering several scenarios of EVs, and proposes countermeasures, in order to achieve coordinated development of the EVs and the grid in the future.

\section{Regional Basis And Advantage For Developing Ev}

The favorable car manufacturing conditions, abundant technology resources lay a good foundation for the development of EV in regional. As one of the 25 pilot cities for the energy conversation and new energy automobiles of China. The charging and replacement integration station, which is the first commercial charging and replacement station in this regional.

By the plan, intelligent network infrastructure for charging $\mathrm{EV}$ and replacing batteries will be completed by 2015.

\section{Typical Charging Mode Of Electric Vehicle}

The charging load characteristics of EV are closely related to its charging modes, which have different effects on load modeling. Based on the technology and application characteristics of EV battery packs, charging modes are divided to three levels of charging-normal charging, fast charging and battery pack replacement system. While, for modeling of EV charging loads 
realistically, the interaction communication between EV and the grid is important to obtain charging curves, three charging modes are presented below.

Distributed Plug and Charge Mode.According to the China actual situation, under this charging mode, the vehicles are charged at home, from a standard outlet in the garage, or on a parking lot at working places. The simplest charging plan is uncoordinated charging, which is such a charging way that EV can be charged any time, any place, without considering the operating of power grid. Restricted by infrastructure, the charging current is usually $0.2-0.5 \mathrm{C}$, so it will take 5$8 \mathrm{~h}$ to achieve $100 \%$ state of charging from $0 \%$.

Centralized Charging Mode.Centralized charging mode means central charging at particular period, including battery exchange station and fast charging station. Fast charging current is several times normal charging current and complete the charging in a short time. For example, when the charging current is $2 \mathrm{C}$, it will take 0.5 hour for SOC to go over $80 \%$ from $0 \%$. In china, presently, battery replacement is the major method, and other charging methods are supplementary.

Intelligent charging Mode.According as EV transmits electricity to the grid or not, intelligent charging is divided to V1G, which is vehicles plug-in with logic/control regulated charge, and V2G, which is vehicles plug-in with logic/control regulated charge/discharge. V2G represents a system by which power can be sold to the power grid by a electric vehicle, as a distributed generator and energy storage equipment. V2G will occur at moments of peak demand or grid fault, so vehicle batteries can be connected to grid in order to optimize the operation of power grid and ensure the safety ${ }^{4}$.

\section{Assumptions conditions}

In section 3, some boundary conditions and assumptions for the analysis of the impact of electric vehicle charging mode on load characteristics are made such as the system condition and power demand forecasting. Based on these assumptions, it is concluded that the development of EV has a huge impact on the load characteristic of local grid ${ }^{5}$.

Boundary conditions. The maximum power system supply of the region is 44.68 billion watts in 2010. Based on the forecasting, annual consumption will be increasing at a rate of $11.8 \%$ during the twelfth five-year period, and the increasing rate will become $6.5 \%$ for demand during the thirteen five-year period and will be around 3.2\% between 2020 and 2030 .

Fig. 1 depicts the daily summer and winter load profiles of the region electric system in 2010. In the typical day of summer, there are two load peaks, around 11:00 and16:00, respectively, because of air-condition load, while two valleys happen around 4:00 in the early morning and 23:006 .

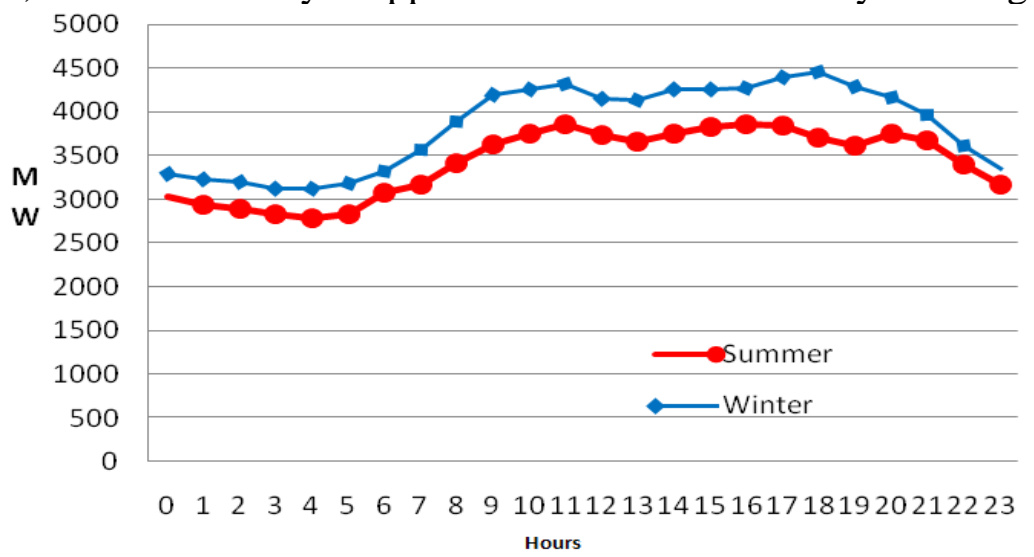

Fig. 1 The daily load profiles of the region electric system from summer and winter in 2010

Asummption.The vehicle annual increase of the region exceeded one million, and vehicle population was over 20 million. The vehicle fleet will amount to 30 million by 2020, and 40 million by 2030 .

With the improvement of facilities and the maturity of market, EV will replace traditional fuel vehicle. The levels of EV penetration have been studied in Axsen and Kurani ${ }^{7}$ and Taylor etal ${ }^{8}$.To analyze the impacts in load profiles, EV penetration of the region is assumed $10 \%$. So the vehicle 
population will be over 300000 by 2020, and 400000 by 2030. Based on operating difference, EVs are divided to four types: private car, public service vehicle, taxies and buses. The mileage and daily consumption of electricity is listed as follows.

Table.1. Mileage and daily consumption of different types of EV

\begin{tabular}{cccc}
\hline Types & Electricity consumption per km(kWh) & Mileage per day(km) & Electricity consumption per day(kWh) \\
\hline Private car & 0.15 & 65 & 10 \\
$\begin{array}{c}\text { Public service } \\
\text { vehicle }\end{array}$ & 0.2 & 100 & 20 \\
Tax & 0.15 & 420 & 70 \\
Bus & 1.3 & 270 & 350 \\
\hline
\end{tabular}

Table. 2. Population of different types of EV

\begin{tabular}{ccccc}
\hline Year & Private car & Public service vehicle & Tax & Bus \\
\hline $\mathbf{2 0 2 0}$ & 240000 & 250000 & 20000 & 15000 \\
$\mathbf{2 0 3 0}$ & 680000 & 40000 & 48000 & 32000 \\
\hline
\end{tabular}

\section{Load profile for EV charging}

\section{Plug and charging mode.}

1) Load profile for charging of electric bus

Considering the situation that buses need to be charged twice per day, centralized charging is usually completed during the spare time, at night, while complementary charging during the business time. Daily load curve for ten electric buses from JiaoZhuang in Linyi Station is investigated, as illustrated in Fig.2.

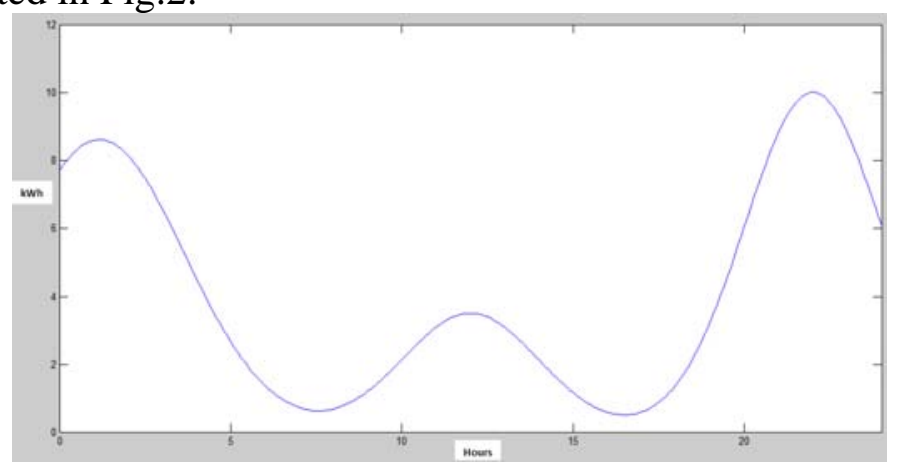

Fig.2 Load profile for charging of electric bus

2) Load profile for charging of tax

Taxes also need to be charged twice per day. Charging usually occurs around shift time, which is 7:00 p.m. and 19:00 a.m. in Shandong and excessive centralization charging may arouse demand peak and traffic congestion. It is necessary to adjust shift time of taxes, which is equally distributed range from the whole day.

3) Load profile for charging of public service vehicle and private car

The public service vehicle and private car owners prefer slow charging mode and do not have the incentive nor the essential information to schedule the charging profile to optimize the grid utilization. According to probability theory, the random variable follows Gaussian distribution. In this paper, Monte Carlo simulations are used to evaluate potential impact and load profile based on projections of the two types of vehicles use, as in

$$
F(t)=e^{-\frac{(t-12)^{2}}{8}}+3 * e^{-\frac{(t-24)^{2}}{18}}(0 \leq t \leq 24)
$$

As shown in Fig. 3, fitting curve of load profile has two peak times, at noon and night, because of the behavior of drivers. The first peak period is at noon, when the batteries are used up after driver's driving all morning. The next charging period is at night, some EVs are immediately plugged in on return from work for being ready to use next morning 9 . 


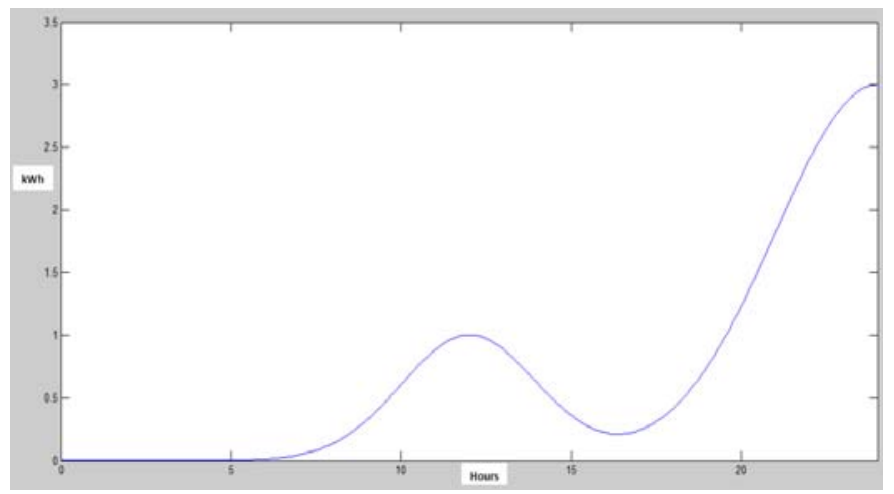

Fig.3 24 hours charge station load curve

\section{Centralized Charging Mode.}

Public service vehicle and private car have characteristics of flexible load, so they can be charged during off-peak time, which means 20-4:00. The maximum charging power is $5 \mathrm{~kW}$. On the contrary, the operating time of tax and bus is inflexible or limited. The charging time of tax should be coordinated with plug and charging mode. For bus, charging could be done during 22:00-4:00, as most closure time is 10:00.

\section{Intelligent V2G Mode.}

Under intelligent V2G charging mode, the equivalent charging load of EV is closely related to the operation of grid system. Fast charging is used by taxes and buses, because of operation limitation. By real-time communication between public service vehicle, private car and the grid, we could coordinately control the charging power and the operation of grid. Peak load shifting capacity depends on the scale and power of EV.

It is assumed that $80 \%$ public service vehicle and private car are involved in peak load shifting during off-peak time, while $20 \%$ at peak time. Considering adjusting capacity $10 \mathrm{kWh}$ per vehicle, the total adjustment effect depends on the daily consumption of electricity of EVs.

\section{Analysis of impact of EV on load characteristics of the Regional power grid}

This paper focuses on how different charging modes influence summer load curve. Fig. 4 represent the load profile under three different charging modes. The detailed indices of load characteristics are listed in Table 3 and Table 4.

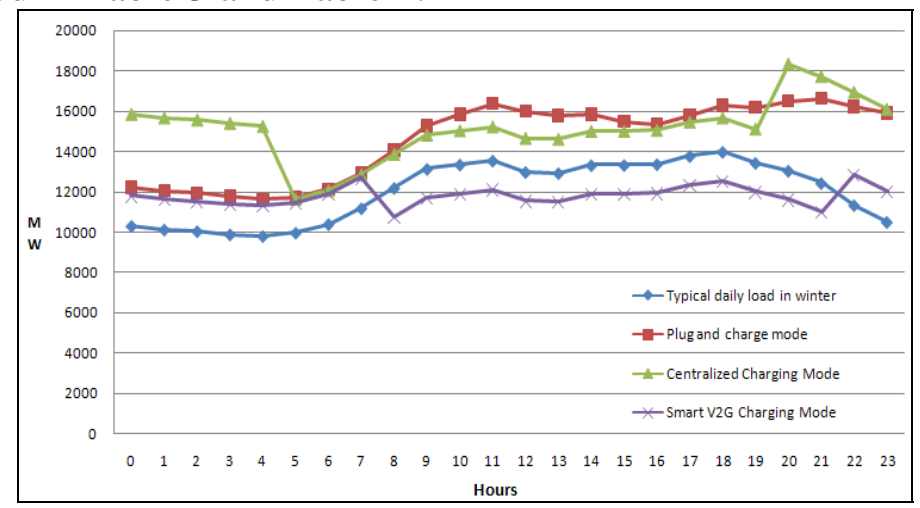

Fig. 4 The impact of three different charging modes on the load profile of winter in 2030

As is shown in Fig.4, development scale of EV in Shandong will be quite large by 2030(accounting for 20\%o) and the peak of load will occur simultaneously with the peak load of the grid system, so it will apparently impact the load characteristics of the power grid in winter. The maximum of load will increase as high as $30 \%$, advanced or postponed. With the larger the scale of EVs become, the more apparent impact from different modes on the grid system.

Annual utilization hours of maximum load had a special change of descend firstly then ascend during the "tenth five-year plan" period, achieve 6762 hours early in the "eleventh five-year plan" period and then gradually declined to 6331 hours until 2010. It is expected to drop sharply in the "twelfth five-year plan” period, because of government's policy. Integration of EVs will influence 
the maximum load distribution, greatly improve product efficiency and increase the maximum load. Annual utilization hours of maximum load are expected to achieve 7200 hours, as shown in fig.5.

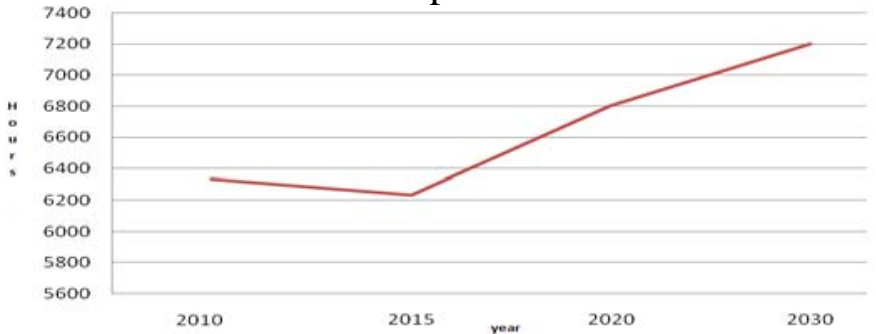

Fig.5 The maximum number of hours of the whole society load

\section{Summary}

In this paper, EV load models of different types in different modes has been built to analyze the impact of electric vehicle charging mode on daily load of Shandong in summer. By 2030, so central charging will result in two peak loads in the morning and evening respectively, advance or postpone the peak time compared with the typical daily load profile without EVs. With micro grid and renewable energy integration and V2G development, it would be interesting to investigate new charging scheduling control and methods.

\section{References}

[1] M. De Nigris, I. Gianinoni, S. Grillo, S. Massucco, F. Silvestro, Impact Evaluation of Plug-in Electric Vehicles (PEV) on Electric Distribution Networks[J], Harmonics and Quality of Power (ICHQP), 2010 14th International Conference, 2010 .Page(s): 1-6.

[2] Gao Ciwei, Zhang Liang, A Survey of Influence of Electrics Vehicle Charging on Power Grid [J], Power System Technology,2011.2,35(2):127-131

[3] Taylor J, Maitra A, Alexander M, Brooks D, Duvall M. Evalution of the impact of plug-in electric vehicle loading on distribution system operations. In: Power\&Energy Society General Meeting 2009;2009.p.1-6

[4] Xin Jianbo,Wen Yubin,Li Rui,I nflunce of widely application of electric vehicle on Jiangxi power grid[J].Jiangxi Electric Power,2010,34(4):1-5.

[5] Teng Letian,He Weiguo,Du Chenggang,et al.Power supply modes for electrical vehicles and their impacts on grid operation[J].East China Electric Power,2009,37(10):1675-1677.

[6] Guille C,Gross G . A conceptual framework for the vehicle-to-grid(V2G) implementation[J]. Energy Policy,2009,37(11): 4379-4390.

[7] Hadley S W,Tsvetkova A. Potential impacts of plug-in hybrid electric vehicles on regional power generation[R]. Tennessee: Oak Rige National Laboratory,2008.

[8] Williamson S, Emadi A, Rajashekara K. Comprehensive efficiency modeling of electric traction motor drives for hybrid electric vehicle propulsion applications. IEEE Transactions on Vehicular Technology July 2007;56(4):1561-72

[9] Kintner M, Schneider K, Pratt R.. Impacts assessment of plug-in hybrid vehicles on electric utilities and regional US power grids part1: technical analysis[C],Electric Utilities Environmental Conference, Tucson, USA, 2007: 1-23. 